\title{
Ópera heroica de dos momias de Chiuchiu, por Aquinas Ried/Reid
}

Heroic opera of two mummies from Chiuchiu, by Aquinas Ried/Reid

\author{
BENJAMÍN BALLESTER \\ Museo Chileno de Arte Precolombino, Santiago de Chile. $\bowtie$ benjaminballesterr@gmail.com \\ [orcid: 0000-0002-7677-717X]
}

RESUMEN

A partir de una breve referencia a la exhumación de dos cuerpos humanos desde un cementerio precolombino en el poblado de Chiuchiu, publicada en un periódico escocés del año 1851, se desenreda una trama profunda de alcances insospechados. Las biografías de su colector, de sus coleccionistas y de los propios cuerpos ahora convertidos en objetos, confluyen en una misma ópera organizada en tres actos que ilustra las trayectorias de los agentes protagónicos de esta compleja red, con sus encuentros y desencuentros. El cruce de sus trayectorias produjo nuevos rumbos y destinos inesperados en sus vidas, orquestados al compás de la red del coleccionismo que ancla firmemente a Atacama con el resto del mundo al menos desde mediados del siglo XIX. Un caso singular de estudio que servirá para reflexionar sobre un fenómeno mayor que involucra no sólo a Chiuchiu sino a todo el desierto de Atacama, para discutir el rol de los objetos precolombinos en la construcción de la identidad de Occidente.

Palabras clave: coleccionismo, antigüedades, diáspora, biografía, red.

\section{ABSTRACT}

From a brief reference to the exhumation of two human bodies from a pre-Columbian cemetery in the town of Chiuchiu published in a Scottish newspaper in 1851, unravels a profound plot of unsuspected scope. The biographies of its collector, its collectionists and the bodies themselves now turned into objects, converge in a single opera organized in three 
acts that illustrates the trajectories of the protagonists of this complex network, with their encounters and misunderstandings. The intersection of their trajectories produced new directions and unexpected destinies in their lives, orchestrated to the rhythm of the network of collectionism that has firmly anchored Atacama to the rest of the world since at least the mid-19th century. A singular case study that will serve to reflect on a larger phenomenon involving not only to Chiuchiu but the entire Atacama Desert, to discuss the role of preColumbian objects in the construction of Western identity.

Key words: collectionism, antiquities, diaspora, biography, network.

\section{OBERTURA}

Occidente se alimentó por generaciones de cultura material del resto del mundo para tejer su identidad y tramar su cultura (Clifford, 1988; Trigger, 1989). Un sutil gesto de creación por contraste, pues lo que estaba en juego era la imagen de la otredad, aquellos que no eran ellos, una figura modelada como un mosaico ensamblado de una infinidad de piezas materiales provenientes de los puntos más recónditos y extraños del planeta (Gosden \& Knowles, 2001; Kelly, 2007; Stocking, 1985). Objetos de arte, patrimoniales, exóticos y antiguos fueron colectados en cada pueblo y paraje visitado por occidentales, bienes acarreados por miles de kilómetros para ser más tarde depositados en museos, galerías, exposiciones universales, mansiones privadas y casas de subasta de las principales metrópolis de Europa y Estados Unidos, entre otras potencias coloniales (Fig. 1).

El resultado de este fenómeno fue el flujo de un inmenso enjambre de objetos que salieron desde sus lugares de origen hacia Occidente de la mano de coleccionistas -colectores y coleccionadores. Esta diáspora creó redes de escala global en la que coparticiparon innumerables agentes humanos (huaqueros, coleccionistas, arqueólogos, tasadores, curadores, etc.) y no-humanos (objetos precolombinos, museos, casas de subasta, galerías de arte, puertos, aduanas, vitrinas, catálogos, naciones, etc.), dando vida a una realidad social labrada en gran medida por el coleccionismo (Byrne et al. 2011; Cheetham, 2012; Larson et al. 2007; Latour, 2005; Law, 1992). En este escenario las biografías de los coleccionistas y de sus colecciones quedaron marcadas de por vida luego de su encuentro, al punto que sus trayectorias se disociaron hacia nuevos rumbos y sus destinos cambiaron para siempre.

El desierto de Atacama fue uno de los polos desde donde más objetos precolombinos salieron del actual territorio chileno, seguido tal vez de Rapa Nui, el mundo mapuche y la Patagonia austral. Un flujo que, si bien comenzó tempranamente tras el primer choque entre nativos amerindios y visitantes europeos (e.g. Cabello, 1984, 1994; Podgorny, 2010; Riviale, 2000a, 2000b), se vio acentuado exponencialmente desde mediados del siglo XIX y hasta la mitad del siglo XX, durante el período denominado la "Era de los Museos" [the Age of the Museums] (Cole, 1982, 1995), debido a la alta demanda de bienes exóticos por parte de 


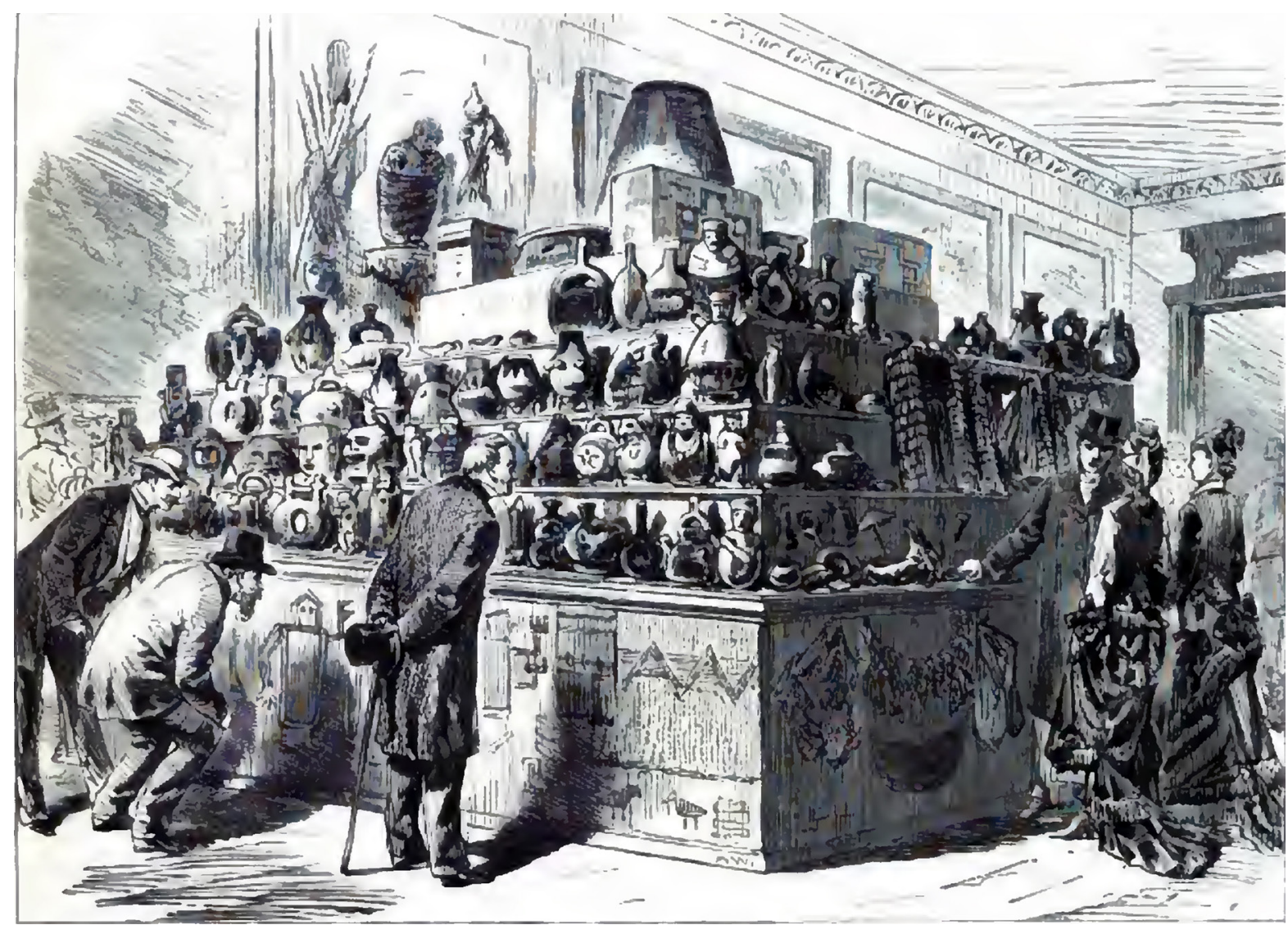

Fig. 1. Ilustración de la exposición Universal de París, Salón de Perú, objetos precolombinos obtenidos por Charles Wiener (Illustrirte Zeitung, 26 de octubre de 1878).

museos y coleccionistas privados de la mayoría de las ciudades occidentales (Gänger, 2009, 2014; González, 2010, 2017; Kohl et al. 2014; Sillar \& Hicks, 2013).

La cantidad de viajeros, expedicionarios, turistas, misioneros, ingenieros, mineros, mercaderes, militares y empresarios foráneos que pasaron o se instalaron en Atacama en este lapso temporal fue inaudita, probablemente la más alta en la historia hasta ese momento. Con ellos llegó el interés por las piezas precolombinas y rápidamente comenzaron las iniciativas para colectarlas desde los sitios arqueológicos con distintos fines, sean éstos científicos, comerciales, artísticos o por mero anticuarismo. Un fenómeno que podría ser descrito hoy como un extractivismo de bienes culturales (Ballester, 2021), y que se materializó en los alrededores de prácticamente todos los florecientes centros poblados de Atacama, en especial aquellos ligados a la minería, actividades portuarias y proyectos energéticos.

Algunos lugares del desierto, sin embargo, fueron más atractivos que otros en este naciente escenario cosmopolita. Es el caso, por ejemplo, del valle de Azapa y el Morro de Arica, o de los puertos salitreros de Pisagua y Taltal, desde donde el número de piezas y cuerpos extraídos es incalculable (e.g. Ballester, 2019; Ballester et al. 2021; Bittmann, 1984; 
Black, 1889; Blake, 1878; Bollaert, 1860; Canales, 1910; Carter et al. 2017; Evans, 1906, 1907; Ewbank, 1855; Flower, 1879; Hutchinson, 1874; Mostny, 1964; Payen, 1856; Rising, 1866; Riviale, 2000b; San Francisco et al. 2020; Skottsberg, 1924; Uhle, 1922; von Tschudi, 1869; Wilde, 1839). El poblado de Chiuchiu, ubicado a orillas del río Loa, es un caso emblemático de este fenómeno, pues sus cementerios y aldeas han sido intervenidos por visitantes foráneos en búsqueda de antigüedades en decenas de oportunidades (Bittmann, 1984; González, 2010, 2017; Latcham, 1938; Mostny, 1952; Thomas, 1978). En la actualidad existe registro de alrededor de treinta ocasiones en que personas excavaron ahí tumbas y colectaron objetos entre las décadas de 1850 y 1970, provenientes de una docena de países y cuyas colecciones se hallan hoy almacenadas en museos de más de veinte ciudades de Europa, Norteamérica, Sudamérica y Chile (Aichel, 1932; Almagro, 1866; Ballester, 2020; Bastian, 1878; Berenguer \& Acevedo, 2015; Bertrand, 1885; Bittmann, 1984; Boman, 1908; Dawson, 1928; Druss, 1978; Flower, 1879; Ibar, 1934; Iriarte \& Renard, 1998; Latcham, 1938; Montell, 1926; Mostny, 1952; Muñoz, 2011; Nichols, 1929; Novoa et al. 1997; Pollard, 1971; Ried, 1851a; Rydén, 1944; San Román, 1896; Spahni, 1963; Thomas, 1978; Torres, 1987; Uhle, 1913; Valdés, 1886; entre otros).

El primer y más antiguo registro conocido de la colecta de objetos precolombinos desde Chiuchiu proviene de un viejo y olvidado documento, publicado en 1851 en un periódico escocés. El relato es de un señor de apellido Ried (1851a) y narra fugazmente su viaje desde Cobija hasta Chiuchiu, en donde tomó dos momias humanas de un cementerio para enviarlas luego a un amigo que era parte de una sociedad científica de la ciudad de Regensburg ${ }^{1}$, en el corazón de la Baviera alemana. Aunque el texto ha sido referido en contadas oportunidades (Bittmann, 1984; Bollaert, 1860; González, 2010, 2017; Larraín, 1972, 1977), poco o nada se sabe acerca de este personaje, menos aún de las razones de su colecta y del destino de ambos cuerpos humanos tras salir de Atacama.

El presente artículo es un intento por develar la biografía de este coleccionista y de su colección (Gosden \& Marshall, 1999; Hoskins, 2006; Kopytoff, 1991), a partir del minucioso estudio de una serie de documentos escritos. Conocer su vida y evocar las circunstancias de su viaje ayudarán a comprender mejor sus motivaciones y pasiones respecto de estos cuerpos humanos ahora convertidos en objetos y mercancías (Charlier, 2016; Ordoñez, 2019). Trazar sus trayectorias fuera del valle donde fueron enterrados siglos atrás servirá para entender su valor final en un nuevo contexto sociocultural, participando desde ese momento en lo que James Clifford (1988) ha denominado el Sistema Arte-Cultura. El caso de Ried y su colección se convertirá al final en un ejemplo entre tantos para reflexionar acerca de la diáspora de objetos precolombinos desde Atacama hacia el resto del planeta y su activa contribución en el modelamiento de la identidad de un Occidente sediento de diferencias y obsesionado por erigir distancias a través de restos materiales.

Llamada también Ratisbona en español. 


\section{ACTO PRIMERO}

El documento en cuestión no fue propiamente publicado por el Sr. Ried, sino por un anónimo que envió una carta de su autoría al periódico escocés Chambers’ Edinburgh Journal el día 8 de marzo de 1851. El mismo texto fue publicado también el mes de mayo de ese año en el Littell's Living Age (Ried, 1851b), un magazine estadounidense que reeditaba selecciones de otros periódicos anglosajones. El artículo posee tres secciones, dos de ellas, al principio y al final, redactadas por quien publica la nota, y entre ambas, aparece la transcripción completa de la carta escrita por el Sr. Ried desde el poblado de Lasana y dirigida a un amigo en Regensburg, Reino de Baviera. Es probable que quien haya divulgado la carta fuera justamente su receptor en Alemania, o al menos un conocido de éste, dado que tuvo acceso a ella y estaba al tanto de detalles ajenos al contenido del texto.

En la carta se señala que el Sr. Ried cruzó el desierto de Atacama en medio de un viaje que comenzó en el puerto de Valparaíso con destino final a la ciudad de Sucre, en ese entonces capital de Bolivia. Según la misiva, los motivos del viaje eran que había sido encomendado como inspector general de los hospitales de dicha naciente república. Tras cuatro días de navegación desde Valparaíso el barco que lo transportaba recala en Cobija. Desde ahí emprende ruta hacia el interior atravesando primero la cordillera de la costa y luego la pampa. En sus palabras se lee el asombro y conmoción de enfrentarse al desierto absoluto, a la ausencia aparente de vida en un escenario en el que reina el viento, el sol y las masas calcáreas. “Aquí y allá”, relata Ried (1851a, p. 158; la traducción es mía), “como única prueba de que alguna vez hubo personas, se ven momias de mulas, de caballos y de seres humanos, secas y descompuestas".

Luego de cuatro días de marcha llega a Calama, según él uno de los lugares más lúgubres y tristes que ha conocido. Una ciénaga en que, si bien se puede dar de beber a las mulas y descansar un poco, el agua es espantosa y genera diarreas. Continúa más tarde su travesía río arriba por el Loa para alcanzar al cabo de dos jornadas el poblado de Chiuchiu, una antigua localidad peruana de cementerios [an ancient Peruvian burying place]. Su descripción de este lugar es sorprendente e ilustra la naturaleza de este enorme sitio arqueológico justo antes de la explosión del extractivismo de bienes culturales en Chiuchiu: “aquí”, narra Ried (1851a, p. 158; la traducción es mía), "en una extensa media luna, están sentados hombres, mujeres y niños -entre 500 y 600-, todos en la misma actitud, y con la mirada vacía ante ellos -algunos caídos, otros parcialmente cubiertos de arena-, (...) muchas mujeres están acompañadas de sus hijos al pecho² (...), hay utensilios de cocina colmados de maíz en torno a ellos”.

Le explica a su amigo que junto a la carta le envía dos cuerpos disecados de estos

El hallazgo de mujeres con bebés en sus brazos en este mismo cementerio fue también documentado por Manuel Almagro como parte de la Expedición del Pacífico (1862-1866), cuerpos que se encuentran depositados y que hasta hace poco eran exhibidos en vitrinas de museos, catálogos y artículos españoles (Minaya \& Rodríguez, 2006; Ortiz, 2019). 
seres humanos, y que más no pudo debido a las dificultades y los altos costos del transporte en el desierto. Agrega que los cajones para estas dos momias debió remitirlos desde Valparaíso, ya que en Cobija no hay disponibilidad alguna de madera. Asimismo, la encomienda incluye muestras de un supuesto meteorito y varios trozos de sal y roca encontrados en los alrededores de Chiuchiu. Finalmente, le pide que deposite todos los ejemplares en el museo de la Zoologisch-Mineralogischer Verein [Sociedad Zoológica-Mineralógica] de la ciudad de Regensburg.

Lasana fue la siguiente parada en su itinerario. Asegura que se trata de una fortaleza de los antiguos peruanos, probablemente la última antes de la conquista de los españoles, construida sobre una lengua de tierra formada por dos brazos del río. Considera que su estilo de construcción es exactamente igual a algunas fortalezas alemanas. Impactado por la buena conservación de los inmuebles, ilustra con lujo de detalle los elementos arquitectónicos del sitio e interpreta la cantidad de habitantes que debió albergar en el pasado. En aquella época Lasana era todavía un lugar desconocido, a tal punto que un sujeto [old negro] que había vivido ahí por casi cuarenta años le afirmó que él era el primer hombre blanco en pisar esas tierras. Ried infiere que los residentes de esta aldea debieron morir de hambre, pues literalmente se camina entre huesos y cráneos, y cada esquina u orificio estaba realmente colmado de ellos.

Es desde este sitio que el Dr. Ried redacta la carta a su amigo en Regensburg. Se ignora si fue escrita a la sombra de uno de los muros de piedra o descansando junto a su carpa en la noche. Su última frase va dedicada a los objetos que acompañan la carta, un complemento clave de una realidad imposible de describir sólo en palabras: "espero que lo que te envié llegue a salvo a su destino, y que ayude a completar una imagen que la pluma de un vagabundo de paso es demasiado débil para dar" (Ried, 1851a, p. 150; la traducción es mía).

"La sensación producida al observar estas momias es muy distinta a la experimentada al ver las egipcias" (Ried, 1851a, p. 150; la traducción es mía). De esta manera comienza la tercera sección del artículo que incluye el relato de quien publica la carta. Deja en evidencia que esta persona no sólo tuvo acceso al documento sino también a los cuerpos humanos que le acompañaban. Se nota en sus palabras que enfrentarse cara a cara con ellos sirvió muy bien para "completar la imagen” de aquello que Ried no logró expresar sobre el papel. Lo que más le asombró fue que las momias de Chiuchiu no tienen la apariencia de estar realmente muertas y que en sus caras aún se aprecia una expresión intensa de sufrimiento, como si por sus cuerpos disecados todavía fluyera algo de sangre caliente. Una semblanza muy distinta a la que exhiben las momias egipcias, cuyos cuerpos embalsamados y delicadamente preparados manifiestan de manera expresa el mensaje de la muerte. A este fragmento le sigue una detallada comparación entre cadáveres de diferentes culturas, un gesto que prueba que su autor era un verdadero entendido en el tema; datos que arrojan luces acerca de su -aúnanónima identidad.

Enseguida dedica algunas frases a las características de los cadáveres de Atacama depositados ya, en ese entonces, en el museo de Regensburg. Uno de los cuerpos sería el de 
un hombre y el otro de una mujer, el primero de un color rojo cobrizo y la segunda de un tono café amarillento. Ambos yacen con las rodillas pegadas al pecho y los brazos junto a las costillas. Las uñas de sus manos y pies, los ojos, así como su cabello y peinado, se conservan perfectamente bien. Para cerrar, el autor ofrece al lector cierta información sobre el donante de la colección y responsable de la carta, el Dr. Ried. Si bien jamás revela su nombre de pila, deja en claro que su origen es escocés, que se educó en Regensburg y que recorrió el mundo entero a lo largo de su vida; el resto es hasta este punto un completo misterio y se requiere de otras fuentes para resolverlo.

\section{ACTO SEGUNDO}

Es probable que el Dr. Ried sea para la gran mayoría de los lectores un completo desconocido. Lo cierto, sin embargo, es que existe una enorme controversia respecto de su vida y obra tanto en Chile como en el extranjero. A nivel nacional su nombre es destacado debido a que fue un importante compositor y dramaturgo de mediados del siglo XIX, responsable de la creación de la primera ópera escrita en tierras chilenas. Telesfora, ópera heroica en tres actos, publicada en 1846, lo convirtió en una figura ilustre en la historia de las artes musicales y teatrales del país, al punto que han dedicado en su honor numerosas biografías y estudios críticos (e.g. Izquierdo, 2011; Keller, 1927; Lira, 1969; Neghme, 1982; Pereira, 1947; Alberto Ried, 1920).

Todas las biografías coinciden en que el nombre de pila del Dr. Ried era Aquinas, pero sobre su apellido existe una gran polémica. Mientras los escritores de la escena chilena aseguran que este era Ried (Cruz-Coke, 1995; Izquierdo, 2011; Keller, 1927; Lira, 1969; Neghme, 1982; Pereira, 1947), otros del ámbito internacional sostienen que su apellido original era Reid y que lo habría cambiado al momento de llegar a Chile (Skinner \& Noden, 2020). Algunos agregan que en su círculo íntimo y antes de llegar al país se le conocía más bien por su primer nombre, James, y no por el segundo.

El desacuerdo sobre su figura no queda ahí, pues tampoco existe consenso acerca de su lugar de nacimiento. Las biografías nacionales concuerdan, por un lado, que Ried era de origen alemán y nativo de la ciudad de Regensburg, en tanto que las extranjeras aseveran que sería escocés (Skinner \& Noden, 2020). La discordia se vuelve aún más sabrosa al considerar que incluso su nieto, Alberto Ried (1920), atestigua que su abuelo habría nacido el año 1810 en el castillo de Strahlfels de la ciudad de Regensburg. Graeme Skinner y Shelagh Noden (2020), por su parte, certifican tras una larga y prolija investigación, que en realidad él nació el 7 de septiembre de 1809 en la ciudad de Aberdeen en Escocia, al norte del Reino de Gran Bretaña. Según estos últimos autores, Reid provendría de una familia muy tradicional católica de Aberdeen y a corta edad habría sido enviado a estudiar como interno al Scots Benedictine Monastery de la ciudad de Regensburg, donde antes ya se habían educado varios familiares suyos. La versión de Skinner y Noden es coincidente con la que acompaña la carta de Ried publicada en el Chambers' Edinburgh Journal, y a todas luces parece ser la biografía que más se ciñe a su verdadera historia. 
Pero este litigio podría ser más que una simple confusión entre sus biógrafos. Todo indica que fue el mismo Ried/Reid -como le llamaremos de ahora en adelante- quien cambió a propósito su apellido y parte de su pasado para construir una nueva identidad a su arribo a Chile. Algo escondía y quiso borrar para siempre, incluso de la memoria de sus propios herederos y familiares. Ya habrá tiempo para volver sobre este punto más adelante, quedémonos por ahora con los detalles de su vida tras su internado en Regensburg. Una vez acabada la escuela, ingresa a estudiar filosofía en una universidad de München, carrera de la cual se gradúa en 1830 (Alberto Ried, 1920). Al poco tiempo se traslada a Londres para continuar con su formación ahora como cirujano en la Royal College of Surgeons, donde se recibe el año 1832 (Lira, 1969; Alberto Ried, 1920). La composición e interpretación musical y literaria fueron pasiones fuertes en su vida tanto en Alemania como en Gran Bretaña (Skinner \& Noden, 2020).

El 17 de noviembre de 1838 Aquinas Ried/Reid se embarca en Londres junto a dos familiares con destino a Sídney, Australia, a bordo del Augustus Caesar, travesía que terminaría en tierras oceánicas el 1 de abril de 1839 (Skinner \& Noden, 2020). En Sídney intenta establecerse como profesor de música, participa de varios eventos artísticos y realiza algunos conciertos, además de tomar un papel protagónico en el coro de la catedral de St. Mary en Hyde Park. En los primeros meses del año 1840 navega hacia las islas Norfolk en un barco para transporte de convictos como asistente de cirujano en un nuevo trabajo. En este asentamiento penal vive cerca de cuatro años hasta que quiebra relaciones con su empleador luego de que éste descubriera que Ried/Reid tenía una aventura con su hija.

Tras un fugaz paso por Sídney, el año 1844 Ried/Reid se embarca nuevamente rumbo a Europa. Un viaje inconcluso pues a mitad de camino y habiendo sólo cruzado el océano Pacífico decide quedarse en Valparaíso (Alberto Ried, 1920). En el puerto se integra rápidamente en los círculos de inmigrantes y descendientes alemanes, en especial aquellos de clase burguesa dedicados al comercio y la diplomacia internacional (Estrada, 2014). Inicia su carrera médica con éxito y ya el 18 de septiembre de ese mismo año estaba participando del coro de la Iglesia Matriz de Valparaíso (Lira, 1969). En 1845 Ried/Reid se casa con Catalina Canciani, oriunda de Génova, Italia, e hija de un gran empresario naviero. Un año más tarde, en noviembre de 1846, la Compañía Lírica del Teatro de la Victoria de Valparaíso anuncia el estreno de Telesfora, ópera heroica en tres actos, compuesta por el Dr. Aquinas Ried (Lira, 1969).

Motivado por sus vínculos con inmigrantes alemanes tomó un rol activo en la colonización del sur del país al punto de escribir algunos libros sobre el tema (Lira, 1969). Dicho ímpetu lo llevó a realizar él mismo un viaje de casi cinco meses y a caballo desde Valparaíso hasta el lago Llanquihue, ida y vuelta (Aquinas Ried, 1920). Una vivencia que incentivó nuevamente su pasión por las exploraciones hacia parajes inhóspitos y que además despertó un interés inusitado por los habitantes nativos de este recóndito territorio.

Tras esta experiencia Ried/Reid acepta en diciembre de 1847 una oferta de trabajo como profesor de química, patología y obstetricia en la Universidad de Chuquisaca en la ciudad de Sucre, de parte del entonces presidente de Bolivia José Ballivián (Lira, 1969; Alberto Ried, 
1920). De acuerdo a su nieto, Aquinas parte junto a su esposa primero en barco hasta Cobija y luego a lomo de mula a través del desierto y cruzando las altas cordilleras en una travesía por tierra de 18 días hasta alcanzar la capital Sucre. Esto significa que, aunque la carta del periódico escocés fue publicada en 1851, el viaje en realidad se llevó a cabo a fines de 1847 y comienzos de 1848, fecha en que habría tomado las dos momias desde el cementerio de Chiuchiu. Lamentablemente Alberto Ried no se refiere a esta singular anécdota.

La estadía en Sucre, sin embargo, resultó ser un completo desastre debido a los problemas políticos de la naciente república y al poco tiempo decide volver a Chile para radicarse definitivamente en Valparaíso (Alberto Ried, 1920). Ahí es designado médico de la ciudad y obtiene en 1849 el título de Médico Cirujano en la Facultad de Medicina de Santiago con una tesis sobre la alimentación y la dieta (Anónimo 1849). Años más tarde logra el título de farmacéutico y abre su propio laboratorio y botica en el puerto (Lira, 1969). Es gracias a esta íntima relación con el mundo de la medicina y por su cercanía a los círculos alemanes que conoce en un viaje a Llanquihue a quien será uno de sus mejores amigos, el doctor Francisco Fonck (Keller, 1927).

El 30 de junio de 1851 Ried/Reid se convierte en uno de los miembros fundadores del Cuerpo de Bomberos de Valparaíso (Fig. 2), el primero y más antiguo de todo Chile (Fredes, 2004). El cuerpo se inauguró con cuatro compañías, dos de ellas de bombas, la $1^{a}$ Compañía

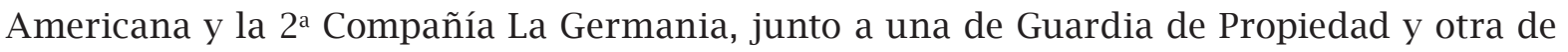
Hachas y Escaleras. Ried/Reid ejerció de forma activa y ocupó cargos altos en la segunda compañía compuesta exclusivamente de inmigrantes alemanes (Skinner \& Noden, 2020), una fachada perfecta para resguardar su segunda identidad.

El brutal bombardeo español sobre el puerto de Valparaíso del 31 de marzo de 1866 fue una verdadera catástrofe para Ried/Reid. Los proyectiles destruyeron por completo su laboratorio, su farmacia y su casa, y con ello perdió toda su biblioteca junto a sus manuscritos musicales, médicos y literarios (Alberto Ried, 1920; Skinner \& Noden, 2020). Salvo algunas de sus óperas, prácticamente todo su legado desapareció y envuelto en la desesperación su vida se volvió amarga hasta el día de su muerte el 17 de mayo de 1869. Desde entonces sus restos yacen enterrados en uno de los cerros de Valparaíso con el debido sepulcro de sus deudos junto a una lápida que inmortaliza su nueva identidad.

\section{ACTO TERCERO}

La nota divulgada en Chambers' Edimburg Journal certifica que los cuerpos de Chiuchiu llegaron hasta Regensburg; queda por delante conocer el devenir de sus historias. La publicación asegura que los materiales precolombinos y los especímenes geológicos iban dirigidos a la Zoologisch-Mineralogischer Verein de Regensburg ${ }^{3}$, una sociedad fundada en 1846 gracias al esfuerzo principal del Dr. Franz Joseph Schuch y que al momento de su conformación ya contaba con 198 miembros, en su totalidad científicos y naturalistas de la ciudad y sus alrededores.

http://www.naturwissenschaftlicher-verein-regensburg.de/historie.html 


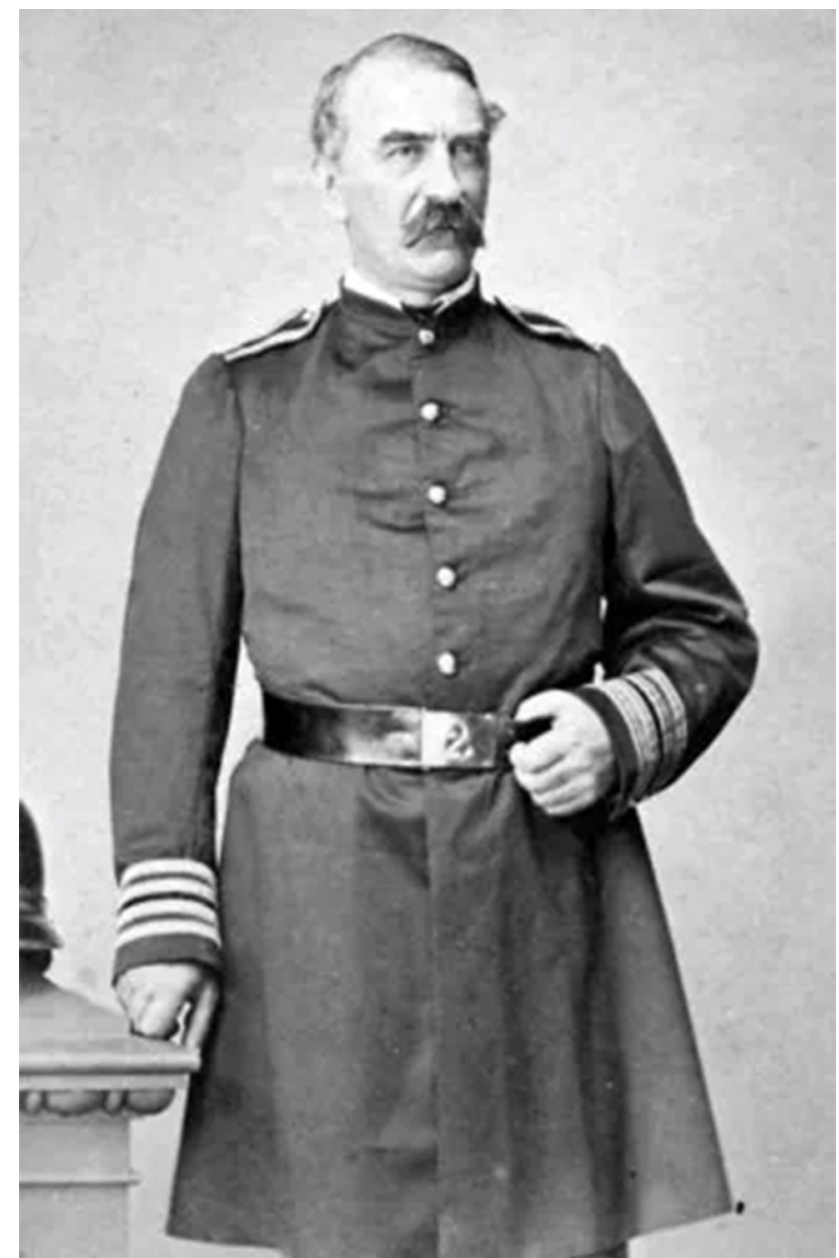

Fig. 2. El doctor Aquinas Ried con su uniforme de la brigada alemana de bomberos de Valparaíso (circa 1860) (Skinner \& Noden, 2020).

Un año después de su fundación la institución comienza a editar un boletín de correspondencias mensuales donde se compendian actividades, miembros vigentes e investigaciones de la sociedad. Ya en el primer número (1847) de la Correspondenz-Blatt des Zoologisch-Mineralogischen Vereins in Regensburg aparece el nombre de "Ried J. Aquinas", doctor y médico en Valparaíso, en la lista de miembros de la asociación. En las páginas iniciales de este mismo número el Dr. Franz Schuch (1847, p. 4; la traducción es mía) presenta en tono rimbombante las contribuciones del Dr. Ried a la sociedad:

"Considero que es mi deber aprovechar esta oportunidad para mencionar, con un honorable reconocimiento, el nombre de un hombre cuyas actividades benefician a nuestra asociación y le serán aún más útiles. Nuestro socio de honor, el Dr. J. Aquinas Ried, que hizo sus estudios en Regensburg y que ha viajado por todo el mundo durante casi 20 años, vive actualmente en el Estado Libre de Chile, y conserva un fiel apego a la ciudad de sus recuerdos 
de juventud. A él le debo una colección de pájaros raros de Chile, de los cuales sólo unos pocos han sido expuestos hasta ahora, la mayoría siguen esperando su exhibición y otros están destinados al intercambio por animales raros. Espero que los próximos meses demuestren lo mucho que la Sociedad debe a este digno miembro, que recorre tanto las llanuras de Chile como las más altas cordilleras, y que me pone en la agradable situación de poder hacer considerables contribuciones a las colecciones de la Sociedad".

Aquinas Ried/Reid no era sólo miembro honorario de la sociedad sino un facilitador habitual de ejemplares naturales y culturales desde los parajes en los que se encontraba alrededor del mundo por intermedio de su amigo Franz Schuch. Esto significa que la a esta altura famosa encomienda de cuerpos humanos disecados desde Atacama no fue más que un envío entre tantos de colecciones exóticas para alimentar a la verein y su museo, y con ellas al conocimiento y la identidad del pueblo de Regensburg. Una situación que queda de manifiesto también en los siguientes números de las correspondencias, donde se detallan nuevas donaciones de colecciones de parte de Ried/Reid desde Chile, como aquella de equinodermos para la sección de moluscos (1848 y 1857) y de minerales de cobre provenientes de Copiapó y Huasco (1854).

Pero es en el noveno número del año 1850 de las correspondencias donde encontramos el texto más trascendente sobre Ried/Reid. Es aquí que el Dr. Schuch (1850) dedica diez páginas en alemán a presentar dos cartas y describir en detalle los dos cuerpos humanos y algunos minerales enviados por Aquinas desde el "altiplano de Bolivia". En este informe Schuch transcribe parte de las cartas y su texto resulta ser exactamente el mismo que fue publicado al año siguiente en el Chambers' Edinburgh Journal. Paso seguido realiza algunos análisis y descripciones físicas y anatómicas de los cuerpos de Chiuchiu (Fig. 3) utilizando la literatura especializada de la época, como a Retzuis, Paris y Morton. Asimismo, compara los hallazgos de Ried/Reid con otros conocidos para la época en Perú, Bolivia, Patagonia, Estados Unidos, México y Brasil. Tanto la reproducción de la carta como su conocimiento experto en temas de anatomía humana comparada sitúan a Schuch como el principal sospechoso de la publicación en el periódico escocés que dio origen a este artículo.

Un año más tarde Schuch (1851) volvería sobre Ried/Reid al publicar una nueva nota sobre sus colecciones de Atacama, esta vez relativa a los minerales enviados desde tierras bolivianas. Especial interés pone en una roca que según el colector sería un fragmento de meteorito encontrado en el desierto, un ejemplar que fue estudiado en detalle por varios expertos en el tema y cuyos resultados alimentan un debate destinado a dar veracidad al hallazgo.

Pero todo indica que estas no fueron las únicas piezas enviadas por Ried/Reid desde Chile ni de Atacama. En el libro Theseaurus craniorum, Catalogue of the skulls of the various races of man, del afamado cranéologo y doctor Joseph Barnard Davis, se describe una serie de cuatro cráneos del área de Charca, en Bolivia, provenientes de un "asentamiento indio abandonado" llamado Lasana y donados por el señor M. D. Aquinas Ried (Davis, 1867, p. 249; 

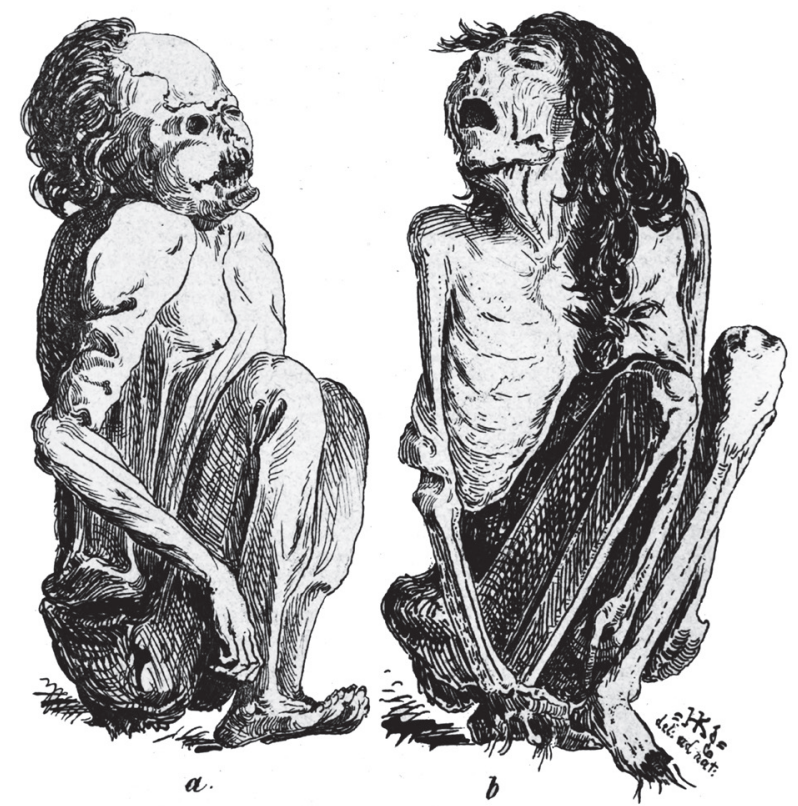

Fig. 3. Ilustración de las dos momias de Chiuchiu depositadas en el museo de Regensburg, Alemania (Schuch, 1850).

la traducción es mía). Una referencia que invita de inmediato a recordar la escena de la carta original de Reid/Ried donde relata su paso por el pukara de Lasana colmado de huesos y cráneos en superficie. En el libro se detalla otra donación de Ried/Reid, esta vez de restos del cráneo y otras partes del cuerpo de un niño patagónico envuelto en una piel de guanaco encontrado en el estrecho de Magallanes; se desconocen las circunstancias del hallazgo y su envío. Es un misterio el vínculo entre el Sr. Davis y Ried/Reid, pero es probable se encuentre en el mundo de la medicina británica, pues no olvidemos que el protagonista de esta ópera estudió en el Royal College of Surgeons de Londres, misma institución de la cual era miembro el cranéologo y que años más tarde le compró toda su colección compuesta de más de 1.800 cráneos y algunos esqueletos; material que aún es conservado en sus museos.

De vuelta en Regensburg, la Zoologisch-Mineralogischer Verein cambió varias veces de locación a lo largo de su historia, y con ella sus colecciones y los cuerpos de Chiuchiu. El año 1857 todas las colecciones se encontraban depositadas en el edificio del tribunal de la ciudad de Regensburg, lugar donde además residía Schuch. En 1883 la sociedad decidió ampliar su giro para convertirse en la Naturwissenschaftlichen Vereines [Asociación de Ciencias Naturales] de Regensburg. Las colecciones resguardadas por la sociedad se trasladaron luego en varias ocasiones: entre 1857 y 1886 estuvieron en la casa de Thon Dittmer, de 1886 a 1893 en la residencia de Schwarz, de 1893 a 1912 en el edificio de la Escuela FilosóficaTeológica ${ }^{4}$ en Agidienplatz, de 1912 a 1920 en Schützenhalle en el parque de la ciudad y de 1920 a 1943 en la galería de arte de este mismo parque. Durante la Segunda Guerra Mundial

En alemán, Gebäude der Philosophisch-Theologischen Hochschule. 

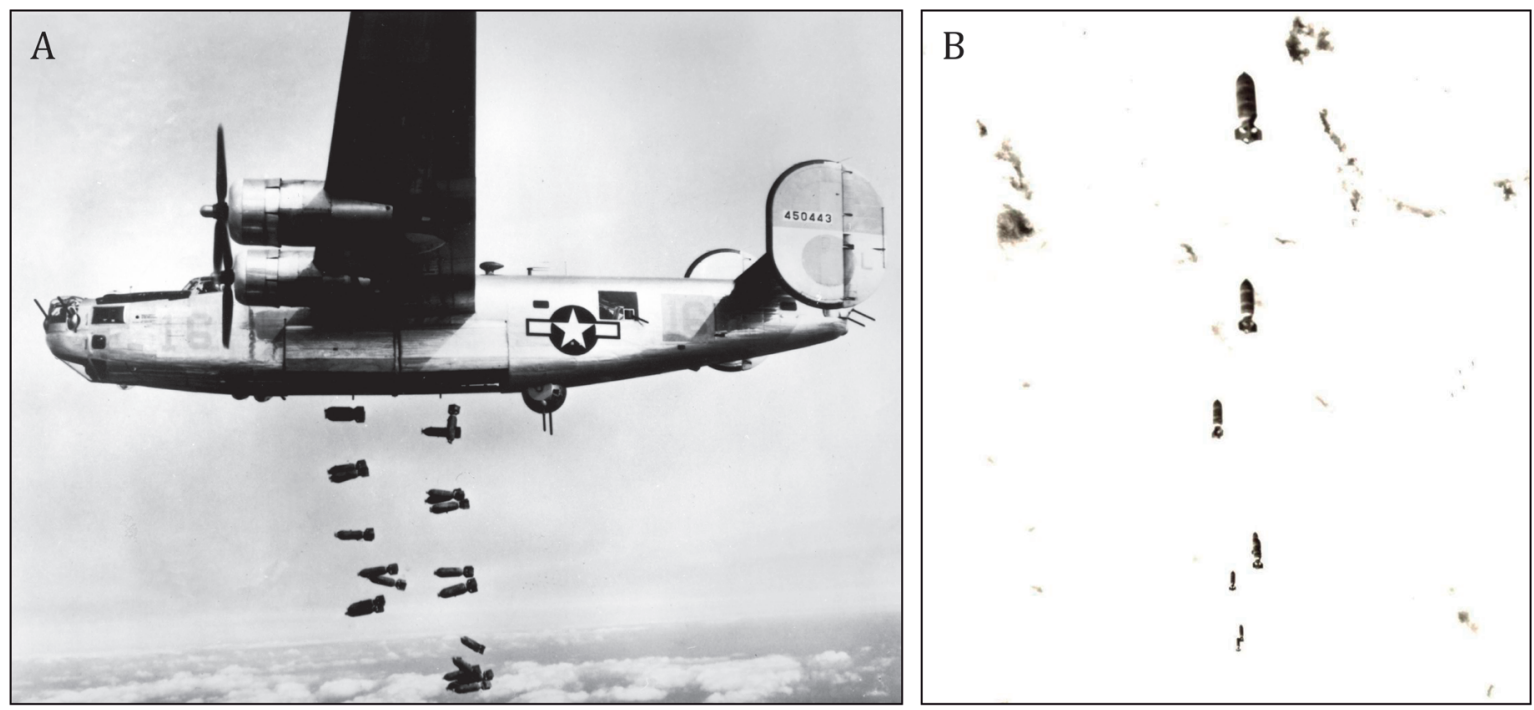

Fig. 4. Tomas del bombardeo aliado sobre Alemania: (A) fotografía de un avión Consolidated B-24 Liberator de la Decimoquinta Fuerza Aérea de Estados Unidos bombardeando las líneas férreas de la ciudad de Muhldorf tan solo cinco días después del ataque a Regensburg, el 19 de marzo de 1945 (UPL 22977, The American Air Museum in Britain); (B) negativo de la fotografía del momento exacto de descarga de las bombas sobre la ciudad de Regensburg el 13 de marzo de 1945 (https://461st.org/Missions/March1945.htm).

este último edificio tuvo que ser desalojado para servir de centro de operaciones a la Reichsluftschutzbund [Liga Nacional para la Protección contra Ataques Aéreos de la Alemania Nazi], por lo que todas las colecciones fueron almacenadas en el ayuntamiento ubicado en el casco histórico de la ciudad.

El día 13 de marzo de 1945, el Mayor Marion C. Mixson, responsable del $461^{\circ}$ Grupo de Bombardeo de la Decimoquinta Fuerza Aérea de Estados Unidos, ordenó a sus escuadrones llevar a cabo la misión número 192 en la ofensiva aliada sobre territorio alemán5. Acostumbrados a atacar objetivos estratégicos de infraestructura industrial y de comunicaciones en toda Europa, el blanco del grupo en esta oportunidad era bombardear el patio de maniobras principal de ferrocarriles de la ciudad de Regensburg. Un convoy compuesto de 569 aviones del tipo Consolidated B-24 Liberator y Boeing B-17 Flying Fortress ${ }^{6}$ salió del complejo aéreo de Foggia en el sur de Italia rumbo a Regensburg, donde el bombardeo se efectuó con éxito siguiendo el método pathfinder y sin enfrentar fuego antiaéreo enemigo (Fig. 4). El masivo ataque dispersó 1.120 toneladas de explosivos sobre el patio de maniobras de ferrocarriles ubicado junto al casco histórico de la ciudad (Schmoll, 2019), lo que destruyó la antigua abadía de Obermünster -que databa del siglo IX- entre otros inmuebles. Tres de las bombas hicieron desaparecer de paso el ayuntamiento que en aquellos años resguardaba las colecciones de la Naturwissenschaftlichen Vereines.

Archivo documental del 461 ${ }^{\circ}$ Grupo de Bombardeo (https://461st.org/Missions/March1945.htm).

USAAF Chronology (http://paul.rutgers.edu/ mcgrew/wwii/usaf/html/Mar.45.html). 
Paradojalmente, tras una veintena de bombardeos británicos y ocho norteamericanos sobre Regensburg entre 1943 y 1945, esta fue una de las ciudades medievales de Alemania que mejor se conservó tras la guerra (Britannica 2020). Una suerte que lamentablemente no vivieron las momias y los objetos precolombinos provenientes de Chiuchiu, perdidos para siempre luego de aquella fatídica incursión militar. Sus restos materiales se encuentran hoy diseminados en la estratigrafía de los suelos de Regensburg, junto a sedimento arrastrado por las aguas del Danubio y mezclados con las cenizas de los miles de muertos dejados por los bombardeos aliados. Nuevamente estos cuerpos anónimos pasaron a ser parte del llamado contexto arqueológico, esta vez lejos de Atacama y ya sin el sepulcro entregado por sus deudos.

\section{Finale}

Las pequeñas anécdotas suelen esconder entramados profundos y de alcances insospechados. Así, lo que en un comienzo parecía ser sólo una fugaz referencia en un periódico antiguo, se convirtió ahora en una ópera compuesta de tres actos, obertura y finale. La clave de la densidad y de la expansión de la trama está en el entrecruzamiento de todas las hebras posibles, bajo la premisa inicial de que una única fuente jamás será suficiente.

El coleccionismo, en tanto fenómeno social, actúa como una red tejida por innumerables actores, tanto humanos como no-humanos, todos y todas responsables de su urdimbre (Byrne et al. 2011; Cheetham, 2012; Larson et al. 2007; Latour, 2005; Law, 1992). En ella, los actores constituyen nodos interconectados entre sí que no logran materializar su agencia de forma aislada y siempre dependen del resto; actúan ensamblados, nunca solos. A lo largo -y ancho- de la trama hay ciertos roles que destacan dentro del universo de actores, al punto de convertirse en verdaderos protagonistas en el devenir de la red, frente a otros que toman papeles claramente secundarios o terciarios, incluso de reparto.

En nuestra ópera heroica los papeles estelares son evidentes: James Aquinas Ried/ Reid y los cuerpos de las dos personas exhumadas desde el cementerio de Chiuchiu. Acompañándolos hay decenas de otros roles y con distinto grado de jerarquía, pero igualmente significativos en la conformación final de esta red de escala global y sin los cuales el desenlace seguramente no habría sido el mismo. Al momento de develar la red sus protagonistas son fundamentales dado que representan nodos cargados de una mayor cantidad de interconexiones con el resto de los actores. Su capacidad sináptica -para usar una analogía neuronal- es sustancialmente más amplia y heterogénea que la del resto, alcanzando no sólo más actores, sino también nodos más lejanos y diversos.

Aquinas Ried/Reid deambuló por el mundo cruzando océanos, islas y desiertos. Era cosmopolita y políglota, de clase alta y educado. Estudió varias profesiones y en distintos países. Fue un hombre viajero, curioso, lector, intelectual, letrado, escritor, compositor, amante del arte y de la naturaleza. Sus círculos de relaciones lo situaban siempre en un marco de semejantes, de su misma clase social o superior, personas de mundo, empresarios 
y latifundistas, profesionales y artistas. Su perfil se puede ilustrar de manera sencilla, están ya todas las herramientas para hacerlo.

A la luz de este perfil es más comprensible entender ahora las razones detrás del gesto de exhumar dos cuerpos humanos disecados de la mitad del desierto y cargarlos cientos de kilómetros para luego enviarlos en barco, con enormes costos asociados y al otro lado del Atlántico, con tal de que fueran estudiados y exhibidos en el lugar donde vivió su infancia. Es innegable que estos cuerpos y objetos precolombinos fueron invaluables para Ried/Reid, ahí radica el motor de esta ópera. Él fue un facilitador de conocimiento empírico sobre todo lo que había y sucedía fuera de esa ciudad, un explorador propio que enviaba cada cierto tiempo señales de vida cargadas de experiencias y noticias exóticas. Era los ojos y la piel de un pueblo entero puesto en el mundo, mediado por un centenar de científicos que actuaban como transcriptores de este material en bruto.

Vemos aquí, en este ejemplo, la mecánica del conocimiento detrás del coleccionismo y la manera a través de la cual se ensamblaban sus partes y engranajes: el inmigrante con dotes de explorador, los científicos y expertos locales con sus respectivas habilidades intelectuales y analíticas, las sociedades científicas e históricas que los articulaban, los museos, las escuelas y universidades, y finalmente los espectadores. Un cuerpo del saber que llenaba un importante vacío en la escena local, pues construía la imagen de todo aquello que estaba fuera de ese lugar, todas las experiencias, sucesos, cosas y seres que ellos no podían percibir de manera directa. El coleccionismo actúa así como un mediador de la realidad externa, y se convierte por lo tanto en un insumo para la construcción también de la realidad interna, de la identidad de quienes viven las colecciones.

La identidad de Occidente se modeló entonces a través de un juego de contrastes protagonizado por fragmentos materiales provenientes de todos los rincones del planeta, exhibidos al gran público en museos, galerías, exposiciones, periódicos, libros y catálogos. Fragmentos todos que transformaron su valor de origen para devenir en objetos de percepción (Alpers, 1991; Pomian, 1990). El coleccionismo forjó así un nuevo mundo simbólico (Blom, 2013), un imaginario de lo exótico y lo desconocido, con el cual se pudo finalmente ordenar a la humanidad -contemporánea y pasada- en una única línea evolutiva orquestada al son del progreso. Occidente ocupó un privilegiado lugar en la cúspide, mientras que el resto de los pueblos se organizó de manera decreciente a lo largo de una interminable gradiente sociocultural. Gracias al extractivismo de bienes culturales y al coleccionismo se pudo construir, materializar y exhibir a la otredad, y Occidente rápidamente tomó a la diferencia y el distanciamiento como criterios básicos para definir su propia identidad.

Es sorprendente que los restos materiales de un pequeño pueblito como Chiuchiu -así como de miles de otros alrededor del mundo- hayan podido ocupar este rol en lugares y personas tan lejanos y distintos. Lo más asombroso es que este singular caso graficado a través de la estructura de una ópera, no es sino uno de un sinnúmero de ejemplos similares, ya que existe registro de más de treinta personas que excavaron o colectaron objetos y cuerpos humanos desde 


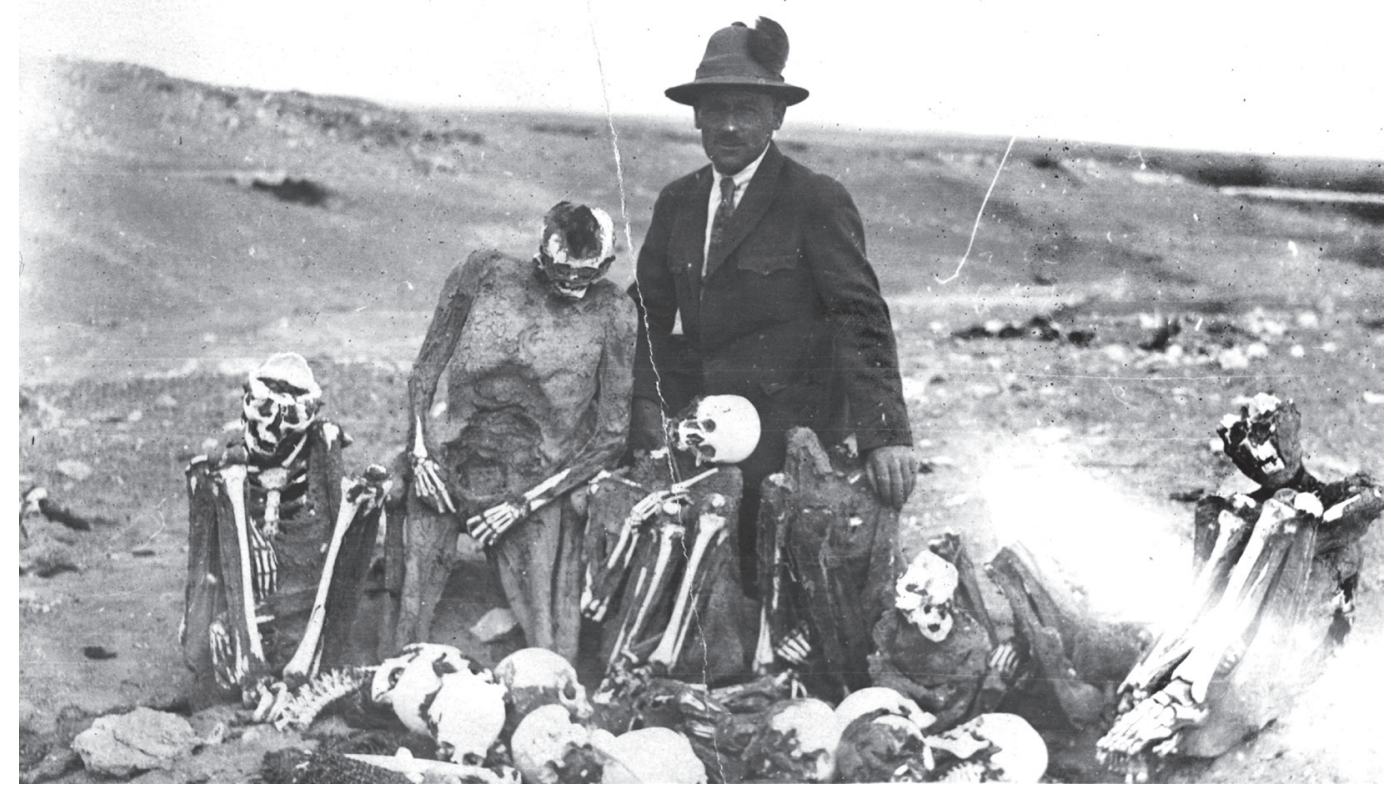

Fig. 5. Fotografía del alemán Hermann Eggers junto a una serie de cuerpos humanos recién excavados en un cementerio de Chiuchiu, en el desierto de Atacama, el año 1925 (fotografía cortesía del Museo Histórico Nacional).

los cementerios de Chiuchiu entre 1850 y 1970 (Fig. 5), materiales que hoy yacen diseminados en más de veinte ciudades en distintos continentes; el extractivismo de bienes culturales desde Atacama es inconmensurable. Debido a esto, los límites de la red expuestos en este relato terminan siendo ficticios y meramente analíticos. Finalmente, la extensión real de la red del coleccionismo alcanza dimensiones que son hoy imposibles de trazar a cabalidad, y los esfuerzos sólo sirven para proyectar algunos tramos y retazos de este enorme tejido que envuelve al planeta.

La noción de biografía es un excelente instrumento para este fin (Gosden \& Marshall, 1999; Hoskins, 2006; Kopytoff, 1991), siempre y cuando se la entienda inmersa en una red y no de forma aislada, esto quiere decir, codependiente de las biografías de los pares con los cuales interactúa. En tal sentido, la biografía de los distintos agentes que componen la trama se encuentra enredada a aquellas del resto de los agentes que integran la red. La biografía del coleccionista está cruzada por la de su colección y viceversa, y cada cual afecta la trayectoria del otro. Esta imbricación de agencias y trayectorias se hizo manifiesta en la ópera heroica de las momias de Chiuchiu, debido a que las vivencias y el destino de estos cuerpos precolombinos disecados se vieron transformados tras su encuentro y posterior relación con James Aquinas Ried/Reid. Lo interesante es que este mismo cruce generó también que la historia de vida de su colector se viera alterada, forjando en sí una nueva trayectoria y destino.

Las momias precolombinas se desplazaron desde su lugar de entierro tradicional en Chiuchiu para acabar enterradas hoy en el suelo de Regensburg en Alemania, mientras que el cuerpo de Ried/Reid se movió a lo largo de su vida desde Aberdeen y Regensburg para 
acabar enterrado en el puerto de Valparaíso. Sus derroteros personales fueron en este sentido inversos y se cruzaron cara a cara en un momento particular de sus historias, encuentro que desencadenó para ellos nuevos destinos que marcaron e inscribieron el resto de sus vidas.

Sin embargo, aunque sus cuerpos experimentaron trayectorias inversas e incluso opuestas entre sí, por alguna extraña razón vivieron un destino compartido: el fin del coleccionista y de su colección fue gatillado por las mismas circunstancias, un bombardeo, en un caso lanzado desde aviones por los aliados y en el otro proyectado desde barcos por la corona española. Americanos bombardeando europeos y europeos bombardeando americanos, qué paradoja. Aunque 80 años y miles de kilómetros separan ambos acontecimientos, lo cierto es que las biografías de estos cuerpos que se conocieron por primera vez en el poblado de Chiuchiu sucumbieron todos ante bombardeos, orquestando un finale para esta ópera heroica marcado por un desenlace común para sus protagonistas.

\section{AGRADECIMIENTOS}

Proyecto ANID-FONDECYT 1210046. Mi más sincero agradecimiento a Nicolás Izquierdo (Chile) y a Graeme Skinner (Australia) por sus consejos, respuestas y anécdotas sobre Aquinas Ried/Reid. A Tanja Stegemann, del Naturkundemuseum Ostbayern de Regensburg (Alemania), por algunos datos e informaciones claves sobre la colección. A Francisco Rivera por mostrarme la fotografía de Hermann Eggers y las momias de Chiuchiu que utilicé en este artículo, y al Archivo Fotográfico del Museo Histórico Nacional (Chile) por permitirme su publicación. A Daniel Quiroz, Francisco Gallardo, Alex San Francisco y José Berenguer por sus lecturas y comentarios.

\section{REFERENCIAS}

Aichel, O. (1932). Ergebnisse einer Forschungsreise nach Chile-Bolivien. Zeitschrift für Morphologie und Anthropologie, 31(1), 1-166.

Almagro, M. (1866). Breve descripción de los viajes hechos a América por la comisión Científica enviada por el Gobierno de S.M.C. durante los años 1862 a 1866. Madrid: Imprenta y Estereotipia de M. Rivadeneira.

Alpers, S. (1991). The museum as a way of seeing. In I. Karp \& S. Lavine (Eds.), Exhibiting cultures. The poetics and politics of museum display (pp. 25-32). Washington: Smithsonian Institution Press.

Anónimo (1849). Memoria presentada a la Facultad de Medicina por don Aquiles Ried el día 18 de marzo de 1849, a fin de obtener el grado de licenciado. Anales de la Universidad de Chile, 225-236.

Ballester, B. (2019). La Colección Paul Thommen del American Museum of Natural History de Nueva York. Taltalia, 12, 109-116. 
Ballester, B. (2020). En busca de la balsa perdida. Boletín del Museo Chileno de Arte Precolombino, 25(2), 141-163.

Ballester, B. (2021). Así cargaron a los que aquí vivieron: excavación, embalaje y transporte de momias y objetos precolombinos en la desembocadura del río Loa [1962]. En B. Ballester y N. Richard (Eds.), Cargar y descargar en Atacama (pp. 93-107). Santiago/París: Ediciones de la Subdirección de investigación del Servicio Nacional del Patrimonio Cultural/Editions IHEAL-CREDA.

Ballester, B., Lemaitre, S., Sepúlveda, M., y Tilleux, C. (2021). Three-beam rafts models on the Atacama Desert coast, northern Chile: museum collections, chronology and miniatures as representations. In D. Elkin \& C. Delaere (Eds.), Underwater and coastal archaeology in Latin America. Miami: University Press of Florida. En Prensa.

Bastian, A. (1878). Die culturländer des alten America. Weidmannsche Buchhandlung, Berlín. Berenguer, J., y Acevedo, N. (2015). Tubos de hueso de ave como implementos chamánicos en el desierto de Atacama, Siglos XII-XV. Boletín del Museo Chileno de Arte Precolombino, 20(1), 51-72.

Bertrand, A. (1885). Memoria sobre las cordilleras del desierto de Atacama. Santiago: Imprenta Nacional.

Bittmann, B. (1984). Introducción: síntesis de la historia de los estudios atacameños. En Actas del XLIV Congreso Internacional de Americanistas, Simposio Culturas Atacameñas (pp. 1-52). Instituto de Investigaciones Arqueológicas R. P. Gustavo Le Paige S.J., Universidad del Norte, Antofagasta.

Black, G. (1889). Notice of a Peculiar Type of Implement found in Ancient Graves in Peru. Proceedings of the Society of Antiquaries of Scotland, 23, 164-166.

Blake, J. (1878). Notes on a collection from the ancient cemetery at the bay Chacota, Peru. Reports of the Peabody Museum of Archaeology and Ethnology, 11, 277-304.

Blom, P. (2013). El coleccionista apasionado. Una historia íntima. Barcelona: Editorial Anagrama. Bollaert, W. (1860). Antiquarian, Ethnologial and other Researches in New Granada, Equador, Peru and Chile, with Observations on the Pre-Incarial, Incarial, and other Monuments of Peruvian Nations. Londres: London Trübner and Co.

Boman, E. (1908). Antiquités de la région Andine de la République Argentine et du désert d'Atacama. Paris: Imprimerie Nationale.

Britannica, T. Editors of Encyclopaedia (2020, May 15). Regensburg. Encyclopedia Britannica. https://www.britannica.com/place/Regensburg

Byrne, S., Clarke, A., Harrison, R., y Terrence, R. (2011). Unpacking the Collection. Networks of Material and Social Agency in the Museum. London: Springer.

Cabello, P. (1984). Expediciones científicas, museología y coleccionismo americanista en la España del XVIII. En Actas del II Congreso de la Sociedad Española de Historia de las Ciencias (pp. 27-49). SEHCYT, Zaragoza. 
Cabello, P. (1994). Los inventarios de objetos Incas pertenecientes a Carlos V: estudio de la colección, traducción y transcripción de los documentos. Anales del Museo de América, 2, 33-61.

Canales, P. (1910). Los cementerios indígenas en la costa del Pacífico. En Actas del XVII Congreso Internacional de Americanistas (pp. 273-297). Buenos Aires: Coni Hermanos.

Carter, C., Vilches, F. y Santoro, C. (2017). South American mummy trafficking Captain Duniam's nineteenth-century worldwide enterprises. Journal of the History of Collections, 29(3), 395-407.

Charlier, L. (2016). Le point de vue des pilleurs. Ethnographie d'une exhumation de momies (Andes boliviennes). Anthropologie et Sociétés, 40(2), 209-226.

Cheetham, F. (2012). An actor-network perspective on collecting and colectables. In S. Dudley, A. Barnes, J. Binnie, J. Petrov y J. Walklate (Eds.), Narrating Objects, Collecting Stories. Essays in Honour of Professor Susan M. Pearce (pp. 125-135). Routledge, Abington.

Clifford, J. (1988). On collecting art and culture. In J. Clifford (Ed.), The predicamento of culture. Twenty-Century ethnography, literature, and art (pp. 215-251). Cambridge: Harvard University Press.

Cole, D. (1982). Tricks of the Trade: Northwest Coast Artifact Collecting, 1875-1925. The Canadian Historical Review, 63(4), 439-460.

Cole, D. (1995). Captured Heritage: The Scramble for Northwest Coast Artifacts. Vancouver: UBC Press.

Cruz-Coke, R. (1995). Historia de la medicina chilena. Santiago: Editorial Andrés Bello.

Davis J. (1867). Theseaurus craniorum, Catalogue of the skulls of the various races of man. London.

Dawson, W. (1928). Mummification in Australia and in America. The Journal of the Royal Anthropological Institute of Great Britain and Ireland, 58, 115-138.

Druss, M. (1978). Environment, subsistence economy and settlement pattern of the Chiu Chiu complex (c. 2700 to 1600 BC) of the Atacama Desert, northern Chile. Unpublished PhD dissertation, Columbia University.

Estrada, B. (2014). Instituciones étnicas alemanas en Valparaíso 1850-1930: una forma de defensa de la identidad cultural. Revista de Historia Social y de las Mentalidades, 18(1), 139-179.

Evans, O. (1906). Notes on the Stone Age in Northern Chile, with special reference to Taltal. Man, 6, 19-24.

Evans, O. (1907). On pottery fragments found at Taltal, Northern Chile. Man, 7, 65-66.

Ewbank, T. (1855). A description of the Indian Antiquities brought from Chile and Peru, by the U.S. Astronomical Expedition. In M. Gillis (Ed.), U.S. Naval Astronomical Expedition to the Southern Hemisphere, during the years 1849-1850-1851-1852, vol. II, (pp. 109-150). Washington: A.O.P. Nicholson Printer. 
Flower, W. (1879). Catalogue of the specimens illustrating the osteology and dentition of vertebrated animals, recent and extint, conteined in the museum of the Royal College of Surgeons of England. London: Printed for the College.

Fredes, C. (2004). 150 años de honor y gloria: Notas para una historia de los Cuerpos de Bomberos de Chile. Junta Nacional de Bomberos de Chile.

Gänger, S. (2009). Conquering the Past: Post-War Archaeology and Nationalism in the Borderlands of Chile and Peru, c. 1880-1920. Comparative Studies in Society and History, 51(4), 691-714.

Gänger, S. (2014). Relics of the past. The collecting and studying of Pre-Columbian Antiquities in Peru and Chile, 1837-1922. Oxford: Oxford Press.

González, J. (2010). Patrimonio, museos y arqueología: de la visibilidad de los pueblos indígenas a la institucionalización de los estudios arqueológicos en el Norte de Chile. Diálogo Andino, 36, 15-32.

González, J. (2017). Atacama Culture Accumulation Cycle: the Tradition of Excavating and Exhibiting in the 19th and 20th Centuries. Journal of Historical Archaeology \& Anthropological Sciences, 2(3), 1-8.

Gosden, C., y Knowles, C. (2001). Collecting colonialism. Material culture and colonial change. Berg, Oxford.

Gosden, C., y Marshall, Y. (1999). The Cultural Biography of Objects. World Archaeology, 31(2), 169-178.

Hoskins, J. (2006). Agency, biography and objects. In C. Tilley, W. Keane, S. Kuechler, M. Rowlands y P. Spyer (Eds.), Handbook of Material Culture (pp. 74-84). London: SAGE Publications.

Hutchinson, T. (1874). Explorations Amongst Ancient Burial Grounds (Chiefly on the Sea-Coast Valleys) of Peru. Part I. The Journal of the Anthropological Institute of Great Britain and Ireland, 3, 311-326.

Ibar, J. (1934). Consideraciones anatómicas sobre cráneos de indios de Paquica y de Chiuchiu. Anales de la Universidad de Chile, 15, 79-105.

Iriarte, I., y Renard, S. (1998). Textiles del norte de Chile en la Colección Echeverría y Reyes del Museo Etnográfico de la Universidad de Buenos Aires. Boletín del Comité Nacional de Conservación Textil, 3, 81-101.

Izquierdo, J. (2011). Totaleindruck o impresión total: La Telésfora de Aquinas Ried como proyecto político, creación literario-musical, reflejo personal y encuentro con el otro. Revista Musical Chilena, 215, 5-22.

Keller, C. (1927). Dr. Aquinas Ried, Leben und Werke. Verlag des Wiffenfchaftlichen Archivs von Chile, Santiago.

Kelly, J. (2007). Art, Ethnography and the Life of Objects: Paris, c. 1925-35. Manchester: Manchester University Press.

Kohl, P., Podgorny, I., y Gänger, S. (2014). Nature and antiquities. The making of archaeology in the Americas. Arizona: The University of Arizona Press. 
Kopytoff, I. (1991). La biografía cultural de las cosas: La mercantilización como proceso. En A. Appadurai (Ed.), La vida social de las cosas. Perspectiva cultural de las mercancías (pp. 89-124). D.F. México: Editorial Grijalbo S.A.

Larraín, H. (1972). Noticias etnohistóricas acerca de las ruinas atacameñas de Chiuchiu y Lasana, provincia de Antofagasta. Cuadernos de Investigaciones Históricas y Antropológicas, 1, 1-19.

Larraín, H. (1977). Cobija y el interior de Antofagasta en 1864. En Actas del VII Congreso de Arqueología de Chile, Tomo II, pp. 429-441. Altos de Vilches: Ediciones Kultrún.

Larson, F., Fetch, A., y Zeitlyn, D. (2007). Social networks and the creation of the Pitt Rivers Museum. Journal of Material Culture, 12(3), 211-239.

Latcham, R. (1938). Arqueología de la Región Atacameña. Santiago: Prensas Universidad de Chile. Latour, B. (2005). Reasempling the social. An introduction to Actor-Network-Theory. Oxford: Oxford University Press.

Law, J. (1992). Notes on theory of the Actor-Network: ordering, strategy, and heterogeneity. System Practice, 5(4), 379-393.

Lira, E. (1969). El doctor Aquinas Ried en el centenario de su fallecimiento. Anales Chilenos de Historia de la Medicina, 11, 73-78.

Minaya, Á., y Rodríguez, S. (2006). Estudio radiográfico de dos momias de Chiu-Chiu (Bolivia) traídas por la expedición española al Pacífico en los años de 1862 a 1866. Revista de la Escuela de Medicina Legal, 2, 28-38.

Montell, G. (1926). An Archaeological Collection from the Rio Loa Valley, Atacama. Skrifter Bind 5, Hefte, Oslo Etnografiska Museum, Oslo.

Mostny, G. (1952). Una tumba de Chiuchiu. Boletín del Museo Nacional de Historia Natural, 26(1), 1-55.

Mostny, G. (1964). Arqueología de Taltal: epistolario de Augusto Capdeville con Max Uhle y otros. Fondo Histórico y Bibliográfico José Toribio Medina, Santiago.

Muñoz, A. (2011). From curiosa to world culture: a history of the Latin American collections at the Museum of World Culture in Sweden. University of Gothemburg, Gothemburg.

Neghme, A. (1982). Obra literaria de los médicos chilenos (IX). Revista Médica de Chile, 110, 1017-1023.

Nichols, H. (1929). Inca relics in the Atacama Desert, Chile. American Anthropologist, 31(1), 130-135.

Novoa, X., Acevedo, N., Mardónez, M., y Lobos, N. (1997). Puesta en valor de la Colección Aníbal Echeverría y Reyes. Noticiario Mensual del Museo Nacional de Historia Natural, 329, 3-12.

Ordoñez, M. (2019). Bundling objects, documents, and practices: Collecting Andean mummies from 1850 to 1930. Museum History Journal, 12(1), 75-92.

Ortiz, C. (2019). Las colecciones de restos humanos de la Expedición del Pacífico y los museos españoles. Asclepio, 71(2), 1-17. 
Payen, A. (1856). Notes sur la composition des yeux de momies péruviennes. Compte Rendu des Séances de l'Académie des Sciences, 43, 707-709.

Pereira, E. (1947). El rincón de la historia: La primera ópera nacional. Revista Musical Chilena, 2(17/18), 53-54.

Podgorny, I. (2010). Naturaleza, colecciones y museos en Iberoamérica (1770-1850). En A. Castilla (Ed.), Museos en escena: política y cultura en América Latina (pp. 53-70). Buenos Aires: Editorial Paidós.

Pollard, G. (1971). The Cultural Ecology of Ceramic-Stage Settlement in The Atacama Desert. PhD. Dissertation, Columbia University, New York.

Pomian, K. (1990). Collectors and curiosities. Paris and Venice, 1500-1800. Cambridge: Polity Press.

Ried, Alberto (1920). Breve biografía del doctor Aquinas Ried. En Diario del viaje efectuado por el dr. Aquinas Ried desde Valparaíso hasta el lago Llanquihue y de regreso (pp. 9-13). Santiago: Imprenta Universitaria.

Ried, A. (1846). Telesfora, ópera heroica en tres actos. Valparaíso: Imprenta del Mercurio.

Ried, A. (1851a). Desert of Atacama. Chambers Edinburgh Journal, 375, 158-159.

Ried, A. (1851b). Desert of Atacama. Littell's Living Age, 366, 382-384.

Ried, Aquinas (1920). Diario del viaje efectuado por el dr. Aquinas Ried desde Valparaíso hasta el lago Llanquihue y de regreso. Santiago: Imprenta Universitaria.

Rising, C. (1866). On the Artificial Eyes of Certain Peruvian Mummies. Transactions of the Ethnological Society of London, 4, 59-60.

Riviale, P. (2000a). Las primeras instrucciones científicas francesas para el estudio del Perú prehispánico (siglos XVIII y XIX). Bulletin de l'Institut Français d'Etudes Andines, 29(1), 29-61.

Riviale, P. (2000b). Los viajeros franceses en busca del Perú Antiguo (1821-1914). Lima: IFEA, Fondo Editorial de la Pontificia Universidad Católica del Perú.

Rydén, S. (1944). Contributions to the Archaeology of the Rio Loa Region. Elanders Boktryckeri Aktiebolag, Góteborg.

San Francisco, A., Ballester, B. y Contreras, R. (2020). Archivo Augusto Capdeville. Obras visuales. Antofagasta: Pampa Negra Ediciones.

San Román, F. (1896). Desierto i Cordilleras de Atacama. Santiago: Imprenta Nacional.

Schmoll, P. (2019). Luftangriffe auf Regensburg. Die Messerschmitt-Werke und Regensburg im

Fadenkreuz alliierter Bomber 1939 - 1945. Buchverlag, Regensburg.

Schuch, F. (1847). Rechenschaft - Bericht. Correspondenz-Blatt des Zoologisch-Mineralogischen Vereins in Regensburg, 1, 2-4.

Schuch, F. (1850). Ueber zmei peruanifche mumien aus der wüste von Atacama, im Hochlande Bolivias. Correspondenz-Blatt des Zoologisch-Mineralogischen Vereines in Regensburg, 9, 129-138. 
Schuch, F. (1851). Meteoreisen von Atakama. Correspondenz-Blatt des Zoologisch-Mineralogischen Vereines in Regensburg, 7, 112.

Sillar, B. y Hicks, D. (2013). South America. In D. Hicks y A. Stevenson (Eds.), World Archaeology at the Pitt Rivers Museum: a characterization (pp. 358-382). Oxford: Archaeopress.

Skinner, G. y Noden, S. (2020). James Aquinas Reid and family. Australharmony, visitado el 20 de abril de 2021. https://www.sydney.edu.au/paradisec/australharmony/reid-jamesaquinas.php

Skottsberg, C. (1924). Notes on the old Indian necropolis of Arica. Meddelanden från Geografiska Föreningen i Göteborg, 3, 27-78.

Spahni, J. (1963). Tombes inédites du cimetière atacaménien de Chiu-Chiu (Chili). Bulletin de la Société Suisse des Américanistes, 26, 2-10.

Stocking, G. (1985). Objects and others. Essays on museums and material culture. Madison: The University of Wisconsin Press.

Thomas, C. (1978). Estudio Arqueológico del Poblamiento Prehispánico Tardío de Chiu-Chiu. Revista Chilena de Antropología, 1, 85-104.

Torres, C. (1987). The Iconography of the Prehispanic Snuff Trays from San Pedro de Atacama, Northern Chile. Andean Past, 1, 191-245.

Trigger, B. (1989). A history of archaeological thought. Cambridge: Cambridge University Press. von Tschudi, J. (1869). Reisen durch Südamerika. 5ster Band. F. A. Brockhaus, Leipzig.

Uhle, M. (1913). Tabletas de madera de Chiuchiu. Revista Chilena de Historia y Geografía, 12, 454-458.

Uhle, M. (1922). Fundamentos Étnicos y Arqueología de Arica y Tacna. Quito: Imprenta de la Universidad Central.

Valdés, S. (1886). Informe sobre el estudio minero i agrícola de la región comprendida entre el paralelo 23 i la Laguna Ascotán, presentado por el Ministro del Interior. Santiago: Imprenta Nacional.

Wilde, W. (1839). Peruvian mummy, recently opened in Dublin. Proceedings of the Royal Irish Academy, 17, 305-315. 